Research Article

\title{
Experimental Investigation of Thermal Modal Characteristics for a Ship's Foundation under $300^{\circ} \mathrm{C}$
}

\author{
Zheyu Ding (D), Hongbai Bai, Yiwan Wu $\mathbb{D}$, Yue Zhu, and Yichuan Shao \\ Engineering Research Center for Metal Rubber, School of Mechanical Engineering and Automation, \\ Fuzhou University, Fuzhou 350116, China
}

Correspondence should be addressed to Yiwan Wu; wuyiwan@fzu.edu.cn

Received 21 February 2019; Revised 19 April 2019; Accepted 28 April 2019; Published 20 May 2019

Academic Editor: Matteo Filippi

Copyright (c) 2019 Zheyu Ding et al. This is an open access article distributed under the Creative Commons Attribution License, which permits unrestricted use, distribution, and reproduction in any medium, provided the original work is properly cited.

How to further reduce vibration and noise is a major challenge for modern ship design. High-temperature environment will significantly influence the mechanical properties (such as elastic modulus and stiffness) of the ship's foundation. These properties will have a serious impact on the inherent vibration characteristics of the foundation. In this paper, a simplified foundation is taken as the research object, and a thermal-vibration joint test system is developed for investigating the thermal modal characteristics of the foundation under different temperatures. The joint test system consists of a transient aerodynamic heating environment simulation system and a vibration excitation and acquisition system. Finite element method (FEM) is used to analyze the distribution of thermal fields. The influence of the ceramic rods and the different ambient temperatures on the modal characteristics of the foundation is studied. The results indicate that the effect of ceramic rods on the modal characteristic of the foundation is negligible. The results also show that the greater the vibration response amplitude is as the temperature increases and the first-order natural frequency does not change, the smaller the second-order natural frequency and the damping ratio will become smaller. The variation of natural frequency and damping ratio of the foundation under different temperature conditions can provide a reliable experimental basis for the design of the vibration and noise reduction of the ship's foundation in the thermal-vibration environment.

\section{Introduction}

The foundation of marine equipment is an important part for connecting the equipment and the ship hull. The vibration transmitted by the equipment to the hull can be reduced by the vibration isolation design of the foundation.

The foundation is made of several plates by welding or bonding. The research results of plate vibration reduction can be used as reference in the vibration reduction design of foundation. In recent decades, extensive studies have been carried out on the vibration isolation technology of the foundation. Adding blocking masses [1], using composite foundation [2], and laying viscoelastic damping material [3] are the main methods for vibration reduction of the foundation. The results of the literature review found that the researches of these methods were mainly carried out at room temperature. However, the power density of the modern ship propulsion system is increasing, and the temperature in the power cabin is rising. Especially, the working temperature of related equipment of the nuclear propulsion system can reach $200^{\circ} \mathrm{C} \sim 300^{\circ} \mathrm{C}$. Therefore, the effect of working temperature on the vibration of the foundation should not be neglected.

The methods for constructing a simulated thermal environment are airflow heating and radiant heating. Compared with airflow heating, radiant heating has the advantages of long heating time, strong heating capacity, multitemperature zone control, etc. Therefore, the radiant heating method was widely used in thermostructural experiments [4-6]. Wu et al. [7, 8] designed heating equipment using quartz lamps and established a thermal-vibrational test system for the thermal mode study of the high-temperature resistant composite airfoil structure of hypersonic aircraft under high-temperature environment of $1100^{\circ} \mathrm{C}$. Zhang et al. [9] studied the vibration characteristics of sandwich structures composed of fiber composite plates and ceramic foam 
elastic layers in high-temperature and large gradient thermal environment. Brown [10] performed a theoretical analysis and numerical calculations of the natural frequency and vibration modes of the composite nozzles of an X-34 FASTRAC rocket in a high-temperature environment. Pan et al. [11] used the self-developed transient aerodynamic heating simulation system to study the thermal shielding performance and three-dimensional thermal deformation behavior of two high-temperature alloy honeycomb sandwich panels in a heat-transformed environment. However, in previous researches, most of the thermal-vibrational joint experiments have only been done for simple structures such as flat plates or straight pipelines. Thermal-vibrational joint experiments with complex structures such as equipment foundation have rarely been reported.

In this paper, the high-temperature transient thermal test system and the vibration test system are combined to simulate the thermal-vibrational joint environment of the ship's foundation. Under the condition of force-thermal coupling, the thermal-vibrational joint experiment of the foundation is carried out, and the variation of the natural vibration characteristics of the equipment foundation under the thermal-vibrational joint environment with temperature is explored, which gives a certain reference value for the stability and reliability design of the ship's foundation in harsh environments.

\section{Experimental Apparatus and Method}

2.1. Foundation. The structural parameters of the foundation are shown in Figure 1. The foundation is made of 45 steel (C45E4). To online monitor the temperature of the foundation, a temperature measuring point is selected at the point A, as shown in Figure 1. The arrangement of excitation point and measurement points is shown in Figure 2. In general, it is enough to get the natural frequencies of the foundation by one acceleration sensor. However, to avoid the influence of temperature nonuniformity on foundation, four measurement points are arranged.

2.2. Experimental System. A thermal-vibration joint test system is developed to investigate the thermal modal characteristics of the foundation. The structural block diagram of the system is shown in Figure 3. This system consists of a transient aerodynamic heating environment simulation system and a vibration excitation and acquisition system. The transient aerodynamic heating environment simulation system is set up for generating the required high-temperature environment. The vibration excitation and acquisition system simulates the external load on the foundation and collects vibration response signals. The two systems complement each other to complete the thermal-vibrational joint test of the foundation.

As shown in Figure 4, the foundation is fixed on the T-shaped groove, which is placed horizontally on the ground, through the bolts. The foundation is heated by the quartz lamp infrared heating arrays which are installed on the left and right sides of the foundation. To improve the heating efficiency, two polished plates, which are made of $310 \mathrm{~S}$ stainless steel and can withstand temperatures up to $1300^{\circ} \mathrm{C}$, are used to fix quartz lamps and reflect the quartz light. Furthermore, three aluminum silicate insulation boards are placed in the front/back/ top of the foundation to provide heat insulation during heating. The electromagnetic exciter, which is suspended above the foundation by two elastic ropes, is connected with the foundation by a ceramic connected pole. In the thermal modal test, the foundation is excited by the electromagnetic exciter from the outside of the high-temperature environment through a force sensor and a ceramic connected pole. Hightemperature acceleration sensors are expensive and require temperature compensation when collecting high-temperature signals. To reduce costs and avoid signal compensation, the acquisition of the vibration signals of the foundation is carried out by ordinary acceleration sensors, which are installed outside the high-temperature environment, through four ceramic rods. The structural parameters of the ceramic rod are shown in Figure 5. Four M8 internal threads, which are $20 \mathrm{~mm}$ in length, at the four measuring points on the rib were processed. The ceramic rods are fixed on the four measurement points at one end and connected to the acceleration sensors at another end by threads.

\subsection{Generation of the Thermal Environment}

2.3.1. Transient Analysis of the Thermal Environment. To ensure that the foundation can be heated to the target temperature, two quartz lamp arrays are arranged on the left and right sides of the foundation. As shown in Figure 6, the quartz lamp filament is a single helical structure and is made of carbon fiber heating element $[12,13]$. The filament parameters used in this experiment are shown in Table 1:

$$
Q=\rho C_{P} \frac{d T}{d t}+\operatorname{div}\left(\lambda \operatorname{grad} T-q_{\lambda=0-\infty}^{r}\right)+Q^{\prime}+\beta T \frac{d P}{d t} .
$$

The electric heating energy $(Q)$ obtained by the quartz filament as the internal heat source can be calculated according to the energy conservation law as follows:where $C_{P}$ is the specific heat capacity of the filament material, $T$ is the filament temperature, $\lambda$ is the thermal conductivity, $P$ is the pressure inside the tube, and $\beta$ is the expansion coefficient.

The four items on the right side of equation (1) are the storage of transient energy, the contribution of heat conduction and heat radiation, the heat generated by viscous dissipation, and the work done by pressure during expansion or compression, respectively. Because the first two items on the right side of equation (1) account for the main part of the electric heating energy of the quartz lamp, the third and fourth items on the right side of equation (1) can be ignored. Therefore, $Q$ can be simplified as

$$
Q=C_{P} m T^{\prime}+A\left(\alpha T^{\prime}+\lambda T^{\prime}+\varepsilon \sigma \theta_{i j} T^{4}\right),
$$

where $m$ is the filament mass, $A$ is the outer surface area of the filament, $\alpha$ is the convective heat transfer coefficient, $T^{\prime}$ is the difference between the filament temperature and the initial temperature, $\varepsilon$ is the filament blackness coefficient, $\sigma$ is the Stefen-Boltzmann constant, and $\theta_{i j}$ is the angular coefficient. 

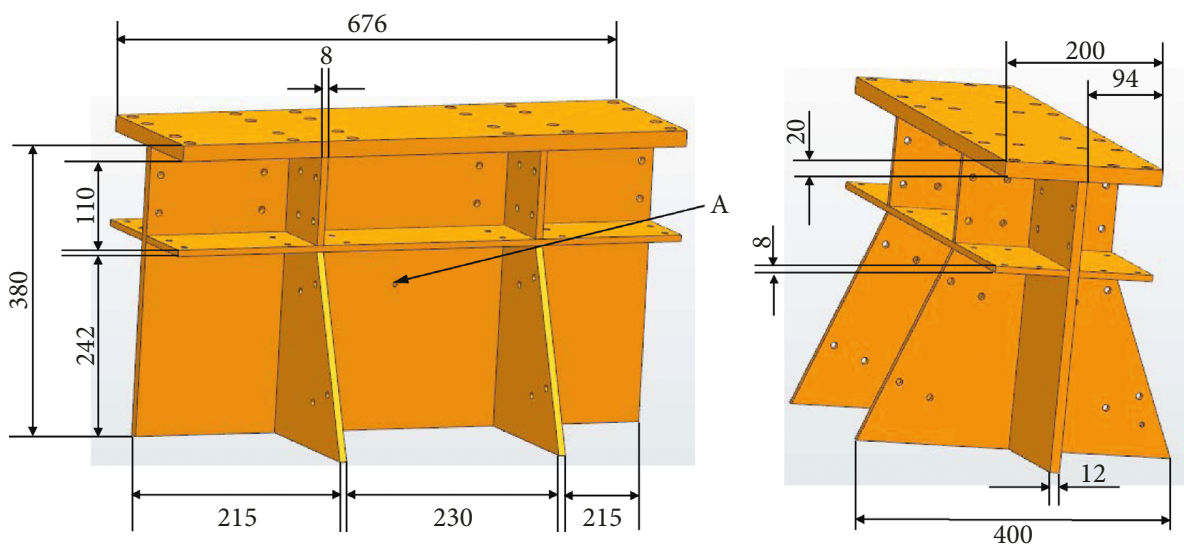

Figure 1: Structural parameters of the foundation.

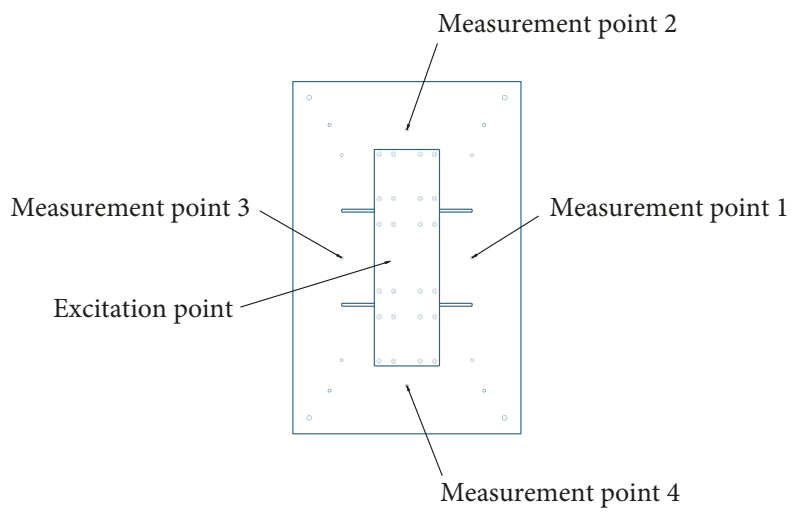

Figure 2: The arrangement of excitation point and measurement points.

The filament is in a vacuum state in the quartz tube. The convection and heat conduction are negligible. Therefore, the quartz lamp releases heat energy by means of radiation heat transfer. Thus, $Q$ can be further simplified to

$$
Q=C_{P} m T^{\prime}+A \varepsilon \sigma \theta_{i j} T^{4}
$$

Whether the thermal field can be heated to the target temperature is determined by the number of quartz lamps. In this investigation, the thermal field was analyzed by the use of the finite element method. To improve the efficiency of the simulation calculation, the three-dimensional model of the thermal environment simulation system is appropriately simplified: the lamp array fixing plate, the aluminum silicate insulation board, and the T-shaped groove are simplified into a flat structure, and all the screw holes on the foundation are removed.

For quartz lamps, if the three-dimensional model retains the spiral structure of its filament, the model will be too complicated and difficult to calculate. Therefore, it is necessary to parameterize and simplify the quartz lamp to an equivalent heat source with the equivalent function. The equivalent heat source needs to ensure that the thermal power before and after the equivalent, the volume of the heat source, and the distance from the heated test piece are equal. The filament spiral is regarded as a cylinder, and the surface area can be expressed as follows:

$$
S=\pi D
$$

where $S$ is the outer surface area of the carbon fiber helix, $D$ is the diameter of the carbon fiber helix, and $L$ is the length of the filament.

By equivalent (4), 16 quartz lamps can be simplified into 16 equal volume cylinders with a volumetric heat flow of $15370 \mathrm{~kW} / \mathrm{m}^{2}$.

The materials used in this simulation process include $310 \mathrm{~S}$ stainless steel, quartz, 45 steel, and aluminum silicate fibers. Their thermophysical properties are shown in Table 2. To improve the accuracy of the simulation, the temperaturedependent material properties of each material are used in finite element software for calculation. In addition, the emissivity of quartz and stainless steel is 0.9 and 0.8 , respectively, and the absorption rates of other materials are set to 0.8 .

To simulate the natural convection between air and components, a convective heat transfer coefficient is applied to the surface of each part of the model [14]. The convective heat transfer coefficient of the external surface of the lamp array fixing plate and the aluminum silicate fiberboard are set to $15 \mathrm{~W} /\left(\mathrm{m}^{2} \cdot \mathrm{K}\right)$. The convective heat transfer coefficient of the inner surface of the lamp array fixing plate and the aluminum silicate fiberboard and the surface of the foundation are set to $8 \mathrm{~W} /\left(\mathrm{m}^{2} \cdot \mathrm{K}\right)$.

The overall model temperature distribution and foundation temperature distribution obtained by transient thermal analysis are shown in Figure 7. As shown in Figure $7(\mathrm{a})$, the inner surface temperature of the aluminum silicate fiberboard is close to $300^{\circ} \mathrm{C}$, and the outer surface is lower than $100^{\circ} \mathrm{C}$. The inner and outer temperatures of the 310 S stainless steel plate are relatively similar, and the maximum surface temperature is $485.15^{\circ} \mathrm{C}$, which is far lower than its melting point temperature $\left(1300^{\circ} \mathrm{C}\right)$. It can be seen from Figure $7(\mathrm{~b})$ that the temperature of the middle part of the upper surface of the foundation rib reaches $320^{\circ} \mathrm{C}$, and the other surface temperatures are around $300^{\circ} \mathrm{C}$, and the temperature distribution is relatively uniform.

The temperature distribution of the top aluminum silicate fiber thermal insulation board is separately analyzed to 


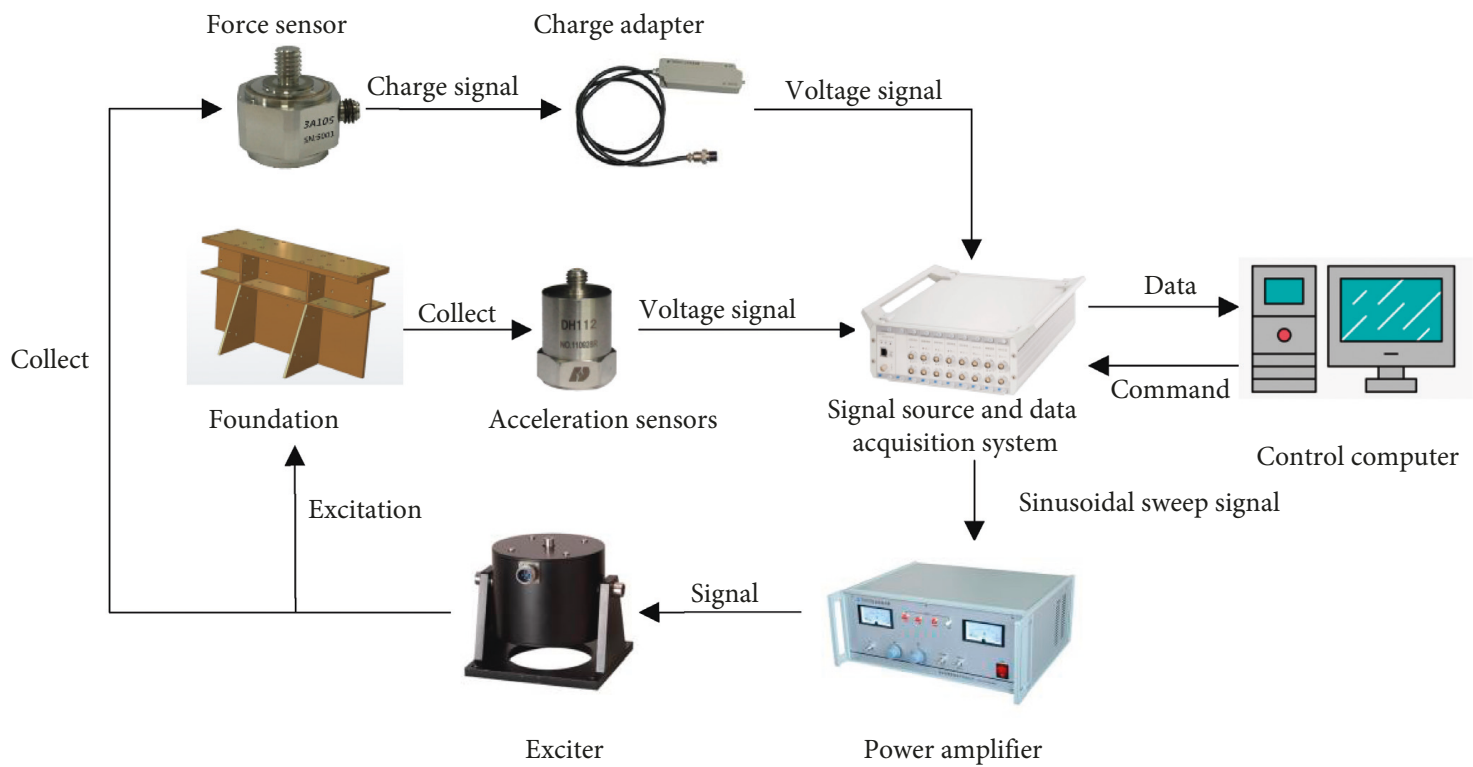

Vibration excitation test system

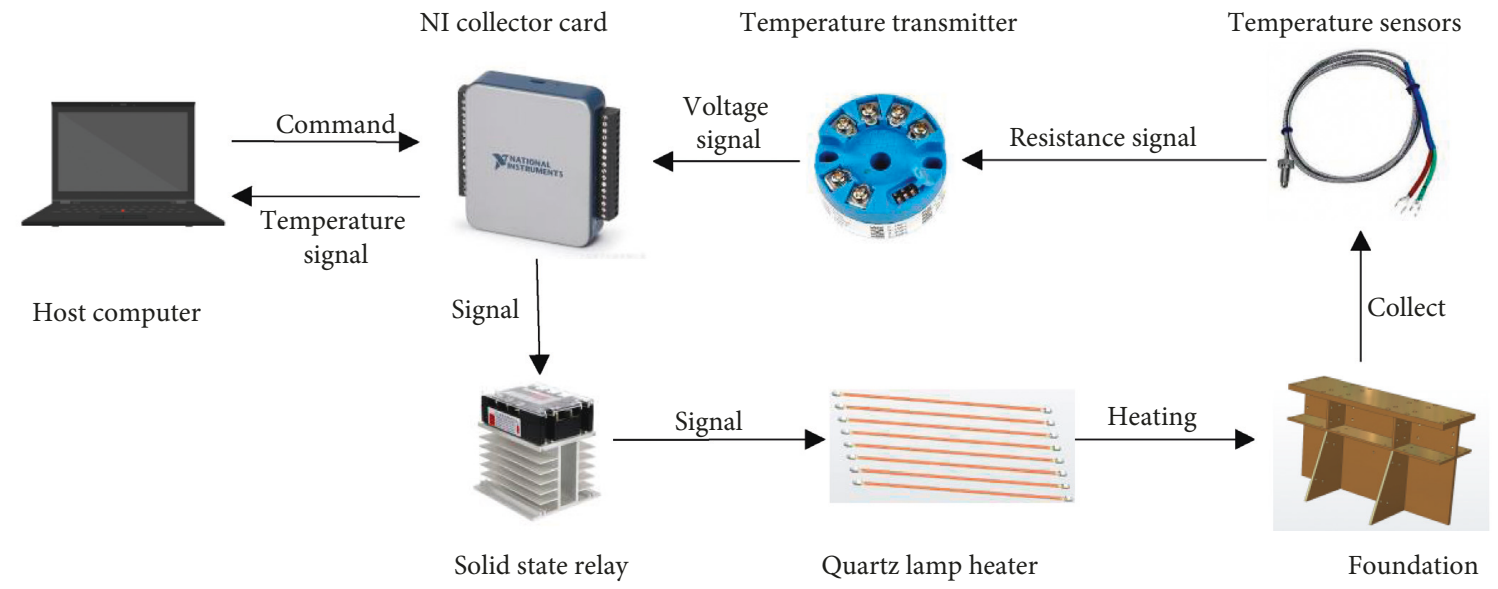

Thermal environment simulation test system

FIgURE 3: Block diagram of the thermal-vibrational joint test system.

ensure the electromagnetic exciter and ordinary acceleration sensors work properly. As shown in Figure 8, the heat of the insulation board is mainly concentrated on both sides of the board, which is near to the quartz lamp arrays, and the temperature in the middle position is lower. The maximum temperature on the insulation board is $92.861^{\circ} \mathrm{C}$, which is lower than the safe working temperature of the ordinary acceleration sensors and the electromagnetic exciter.

\subsubsection{Experimental Verification of Thermal Environment} Simulation System. A self-developed temperature control subsystem based on LabVIEW ${ }^{\circledR}$ is employed to generate the high-temperature environment $[15,16]$. The hardware connection is shown in the bottom half of Figure 4 . In the thermal modal test, the foundation is heated by two quartz lamp arrays simultaneously, and the temperature of the foundation is collected in real time through the temperature sensor and high-speed data acquisition card. Host computer controls the quartz lamp arrays based on the signal collected through the NI acquisition card and the solid-state relay. Then, the quartz lamp arrays are controlled to turn on and off to keep the temperature of the foundation constant.

In order to verify the correctness of transient thermal analysis in the previous sections, the foundation is heated to $300^{\circ} \mathrm{C}$ directly. The selection of the temperature measurement point has been described in Figure 2. As shown in Figure 9, there gives a comparison between the actual temperature rise curve and the simulated temperature rise curve. The heating curve can be divided into three stages: start heating, constant heating, and keep temperature. At the start heating stage (temperature $<60^{\circ} \mathrm{C}$ ), the lamps are just energized, and the actual temperature of the 


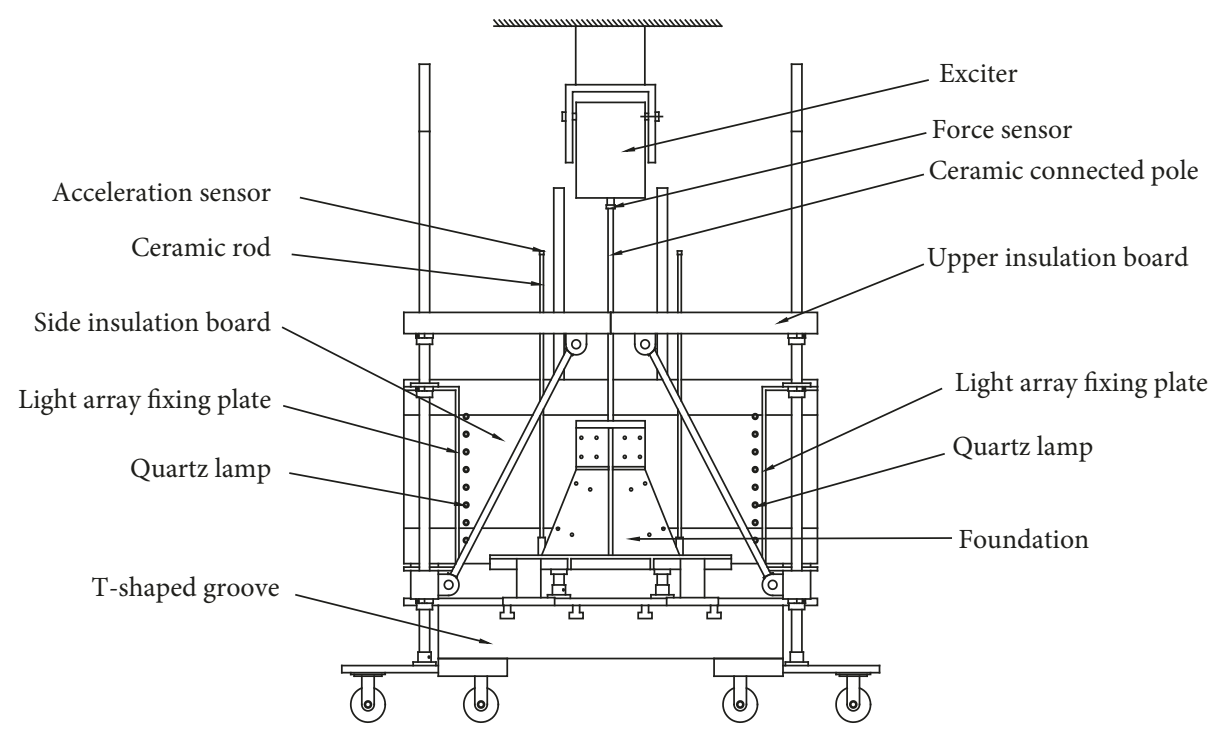

FIGURE 4: Schematic of thermal-vibration joint test setup.

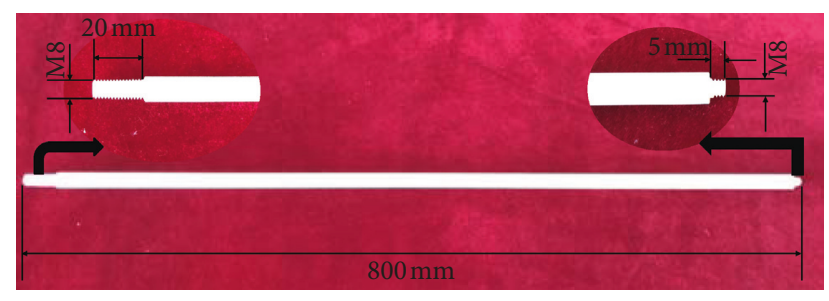

FIgURE 5: Structural parameters of the ceramic rod.

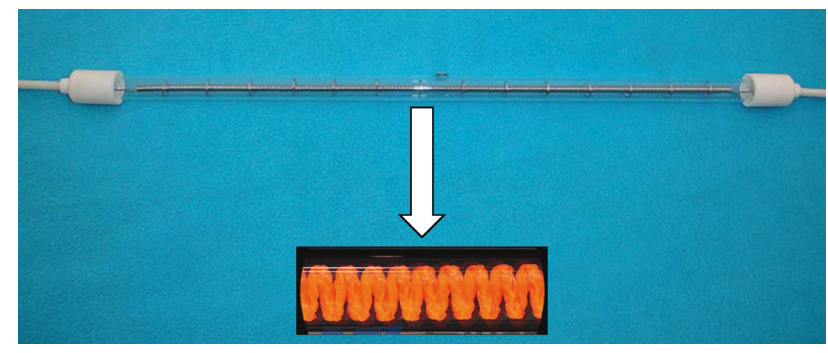

FIgURE 6: Quartz lamp and its filament.

TABle 1: The parameters of the quartz lamps.

\begin{tabular}{lccc}
\hline Voltage $(\mathrm{V})$ & Power (W) & $\begin{array}{c}\text { Filament } \\
\text { diameter }(\mathrm{mm})\end{array}$ & $\begin{array}{c}\text { Filament } \\
\text { length }(\mathrm{mm})\end{array}$ \\
\hline AC 220 & 3000 & 0.45 & 1200 \\
\hline
\end{tabular}

foundation is $2 \sim 3^{\circ} \mathrm{C}$ lower than the simulated temperature. At the constant heating stage $\left(60^{\circ} \mathrm{C} \sim 299^{\circ} \mathrm{C}\right)$, the actual temperature rise curve coincides with the simulated temperature rise curve. At the keep temperature stage (target temperature $300^{\circ} \mathrm{C}$ ), the host computer starts to control the on and off of the lamp arrays; therefore, the actual temperature is maintained at about $300^{\circ} \mathrm{C}$. But the simulation temperature will rise again because the heat source is constant (not be controlled).
2.4. Vibration Excitation and Acquisition System. As shown in Figure 4, the vibration excitation and acquisition system is composed of four ordinary acceleration sensors, a force sensor, a charge amplifier, a multichannel data acquisition system, controlling computer, a power amplifier, and an electromagnetic exciter. The multichannel data acquisition system is DH5922N dynamic signal acquisition system, which was produced by Donghua Testing Co., Ltd. DH5922N is composed of 32 input channels and 2 output channels. When the system runs, the controlling computer controls the output channel of DH5922N and outputs the sine sweep signal to the power amplifier to generate external stimulus load on the foundation. The external stimulus load is monitored by the force sensor, which is mounted between the exciter output and the excitation rod by means of a threaded connection. The vibration signals of the hull are measured by four ordinary sensors. These vibration response signals are collected in real time by the input channels of the DH5922N, and then, they are sent to the controlling computer for storage and subsequent analysis after processing.

2.5. Analytical Methodology of the Acceleration. In this paper, acceleration admittance is used to describe the vibration acceleration response caused by the unit structure under unit force excitation. The larger the acceleration admittance is, the greater is the vibration response transmitted by the foundation structure. Acceleration admittance is defined as follows:

$$
H=20 \cdot \log \left(\frac{a}{F}\right),
$$

where $a$ represents the acceleration on the hull structure below the foundation in which the benchmark value is $10^{-6} \mathrm{~m} / \mathrm{s}^{2}$ and $F$ is the excitation force on the foundation.

In order to study the influence of the effect of equal excitation force on the vibration transmission at different 
TABLE 2: Material thermophysical properties.

\begin{tabular}{lccccccccc}
\hline \multirow{2}{*}{ Material } & Density $\left(\mathrm{kg} / \mathrm{m}^{3}\right)$ & \multicolumn{3}{c}{ Specific heat capacity $(\mathrm{J} /(\mathrm{kg} \cdot \mathrm{K}))$} & \multicolumn{3}{c}{ Thermal conductivity $(\mathrm{W} /(\mathrm{m} \cdot \mathrm{K}))$} \\
& $20^{\circ} \mathrm{C}$ & $20^{\circ} \mathrm{C}$ & $100^{\circ} \mathrm{C}$ & $200^{\circ} \mathrm{C}$ & $300^{\circ} \mathrm{C}$ & $20^{\circ} \mathrm{C}$ & $100^{\circ} \mathrm{C}$ & $200^{\circ} \mathrm{C}$ & $300^{\circ} \mathrm{C}$ \\
\hline 45 & 7824 & 472 & 480 & 498 & 524 & 47.68 & 43.53 & 40.44 & 38.13 \\
$310 \mathrm{~S}$ & 8030 & 502 & 508 & 517 & 528 & 13.8 & 14.3 & 15.7 \\
Quartz & 2200 & 213 & 213 & 213 & 902 & 3.31 & 3.67 & 3.94 & 4.21 \\
Aluminum silicate & 100 & 900 & 943 & 997 & 1040 & 0.035 & 0.048 & 0.061 & 0.073 \\
\hline
\end{tabular}

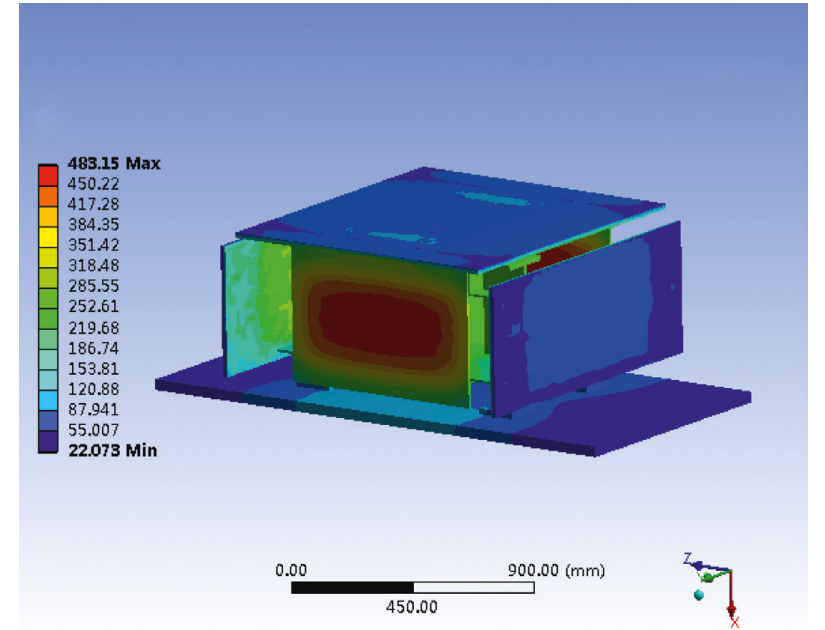

(a)

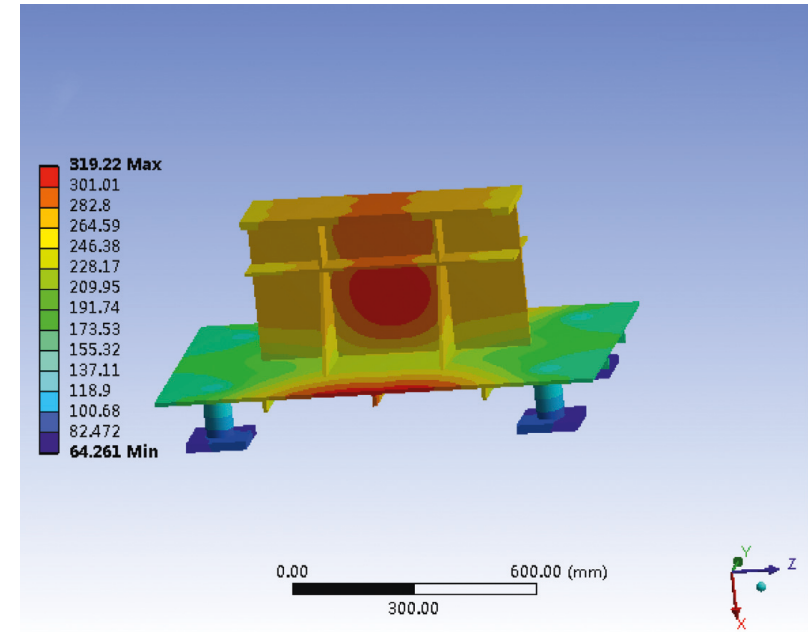

(b)

Figure 7: Result of transient thermal analysis. (a) Temperature distribution of overall model and (b) foundation.

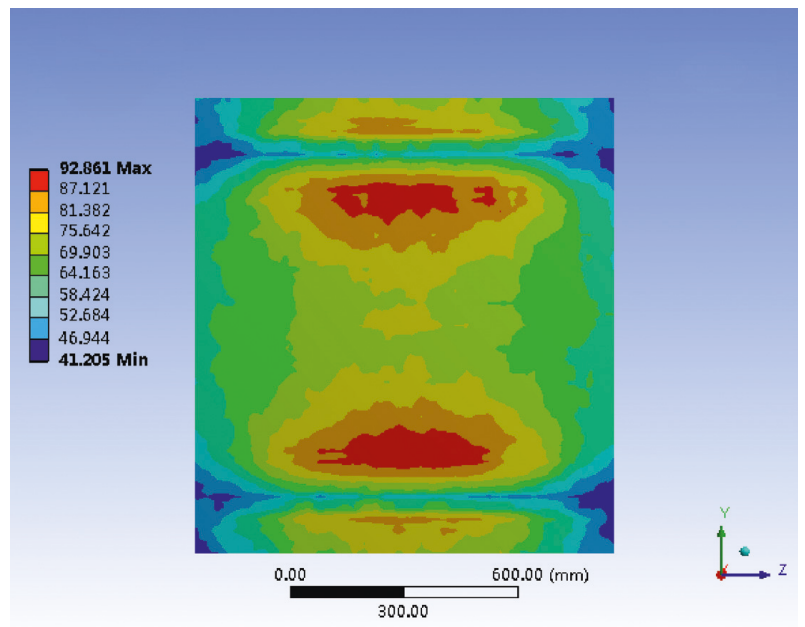

FIgURE 8: Surface temperature distribution of the top aluminum silicate fiber insulation board.

temperatures, the admittance characteristics at each temperature have been analyzed by experiments. The size of the admittance illustrates the ease of structural vibration caused by the same exciting force. The larger the admittance is, the more likely the structural vibration is caused.

2.6. Thermal-Vibration Joint Test Method. Firstly, install the foundation and the thermal-vibration joint test

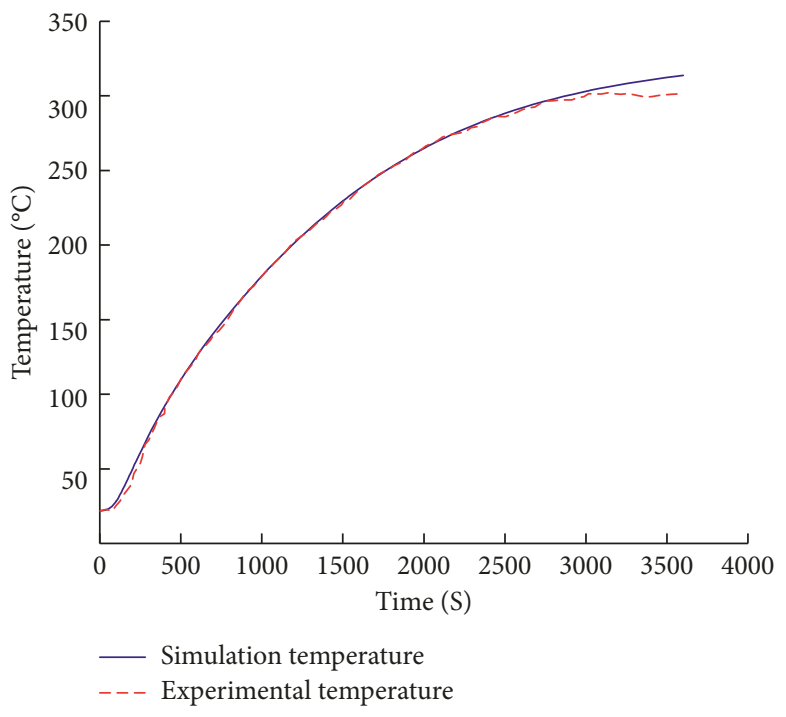

FIGURE 9: Contrast of actual and simulated temperature rise curve.

system as mentioned above. Secondly, heat the foundation to the target temperature and maintain the target temperature for 10 minutes. Thirdly, send sine sweep signals to the power amplifier and then drive the electromagnetic exciter to vibrate the foundation. Finally, collect, store, and process the vibration signals of the hull. 
2.7. Evaluation Indexes. In this investigation, natural frequency $\left(\omega_{\mathrm{n}}\right)$, modal shape, and damping ratio $(\xi)$ are the three thermal modal characteristic parameters of the foundation that we are concerned about.

When the structural system responds to external transient excitation, it will naturally vibrate at a specific frequency [17]. This specific frequency is called the natural frequency of the structure. Usually, a structure has many natural frequencies. For an undamped single degree of the freedom system, the natural frequency calculation formula is defined as follows:

$$
\omega_{\mathrm{n}}=\sqrt{\frac{k}{m}},
$$

where $k$ is the stiffness coefficient, $m$ is the mass of the object, and $\omega_{\mathrm{n}}$ is the natural frequency.

It can be seen from equation (6) that the natural frequency of the structure is affected by the stiffness distribution and the mass distribution. For the foundation, the temperature will affect the change in stiffness, which in turn causes the structural damping ratio to change.

The panels, webs, brackets, and connecting plates on the foundation are crisscrossed, and the vibration waveforms are transformed, reflected, scattered, and refracted at various joints due to structural abrupt changes. In addition, the structural damping of the foundation also influence propagation of the vibration waveforms which makes vibration sound radiation reduced and vibration energy attenuated [18-20].

To further study the effect of temperature on the energy consumption of the foundation, the damping ratio change of the foundation at different temperatures can be obtained by the half-power method through the frequency response curve obtained in the experiment. As shown in Figure 10, at the left and right sides of the peak value $\omega_{\mathrm{n}}$ of the inertia rate curve, the two points of $\sqrt{2} / 2$ times of the peak amplitude are found, which are called "half power points," and then, the damping ratio of the foundation can be obtained by the following formula:

$$
\xi=\frac{\omega_{2}-\omega_{1}}{2 \omega_{\mathrm{n}}},
$$

where $\omega_{1}$ and $\omega_{2}$ are the frequency values at the half-power point and $\omega_{\mathrm{n}}$ is the resonant frequency.

\section{Thermal-Vibration Joint Test Results and Discussion}

3.1. Finite Element Analysis. Before the thermal-vibrational joint test, the finite element method was used to analyze the modal shape of the foundation and the interval between the first-order and second-order natural frequencies of the foundation. These parameters can be determined in advance to provide assistance for subsequent experiments.

The first-order and second-order modes obtained by modal analysis of the foundation under room temperature are shown in Figure 11. As can be seen from the figure, both the first-order and second-order modal shapes of the foundation are integrally twisted, and their natural

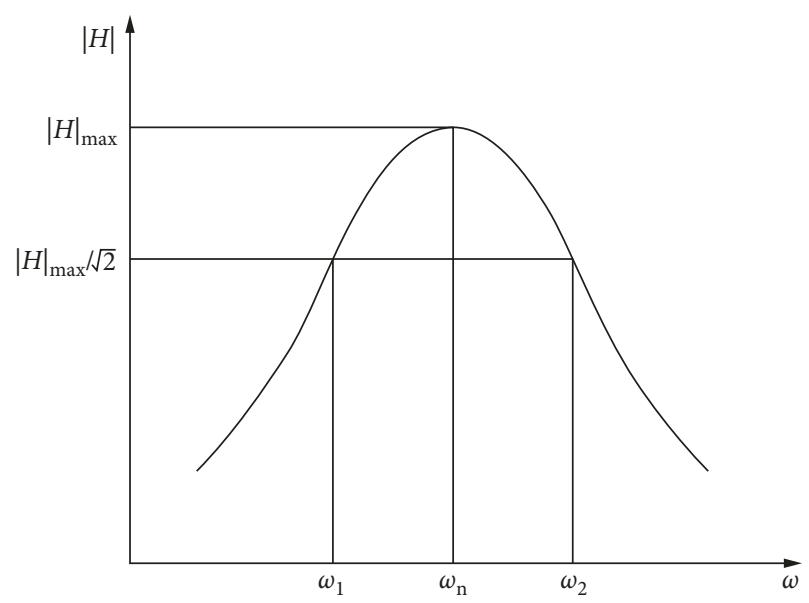

Figure 10: Inertia rate curve.

frequencies are $90.57 \mathrm{~Hz}$ and $337.78 \mathrm{~Hz}$, respectively. Compared with the panel, the web, the connecting plate, and the bracket, the deformation of the rib is the largest, and so, the acceleration value acquired by the acceleration sensor on the rib is the largest. At the same time, a conclusion can be made by the modal analysis of the foundation that the firstorder natural frequency of the foundation is about $90 \mathrm{~Hz}$ and the second-order natural frequency is about $300 \mathrm{~Hz}$. Therefore, the frequency of the sine sweep signal is set to $50-400 \mathrm{~Hz}$.

\subsection{Analysis of the Influence of Ceramic Rods on the Natural} Frequency and Damping Ratio of the Foundation. To ensure the accuracy and authenticity of the thermal-vibration joint test data, the influence of the ceramic rod on the modal characteristics of the foundation should be analyzed. Because the acceleration sensors are not high-temperature sensors, the influence of the ceramic rod on the foundation was analyzed only at room temperature $\left(20^{\circ} \mathrm{C}\right)$. Before the test started, four acceleration sensors were placed directly on the four measurement points (Figure 2). And then, the foundation was excited by the electromagnetic exciter, and the acceleration signals were recorded by the DH5922N. After the test was completed, the ceramic rods were installed between the acceleration sensors and the four measurement points (foundation). Then, the same excitation force was used to excite the foundation again by the electromagnetic exciter. The acceleration signals were collected and compared with the previous one. As shown in Figure 12, the acceleration value without ceramic rods is greater than that after adding ceramic rods. But the data error of the two tests is less than $5 \%$. Thus, the influence of the ceramic rod on the amplitude of the vibration response can be ignored. At the same time, the difference of natural frequencies between before and after adding ceramic rods is less than $1 \mathrm{~Hz}$.

Under room temperature, the damping ratio of the foundation with ceramic rod is 0.0301 , and the damping ratio of the foundation without ceramic rod is 0.0308 . The deviation of the damping ratio is $2.27 \%$. It means that the 
COORD, magnitude
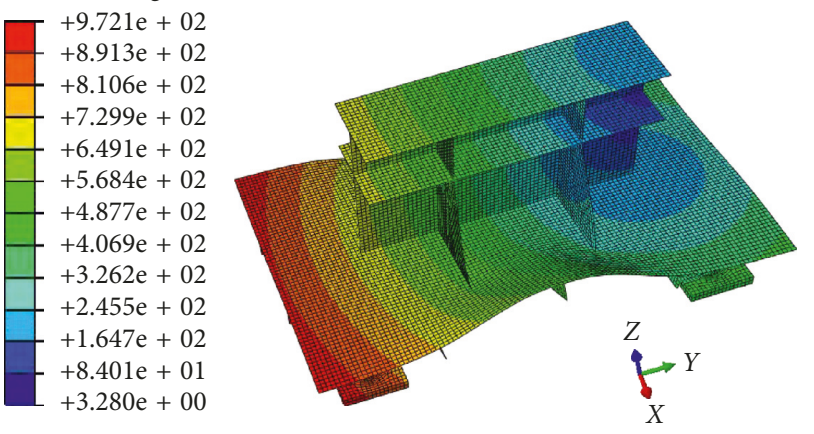

(a)
COORD, magnitude
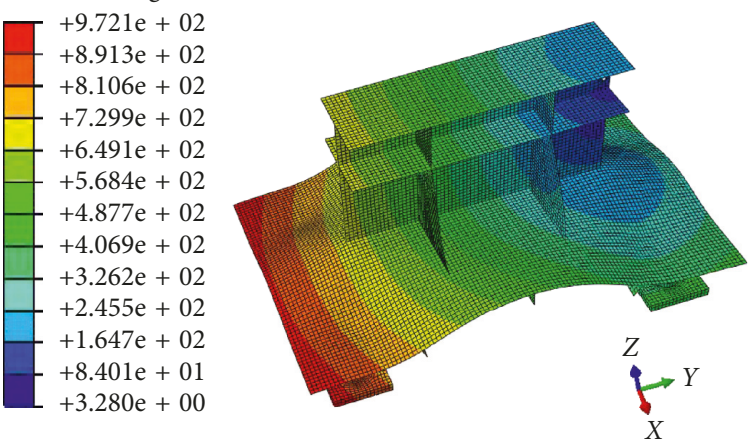

(b)

FIgURE 11: Modal shape of the foundation. (a) First-order modal shape. (b) Second-order modal shape.

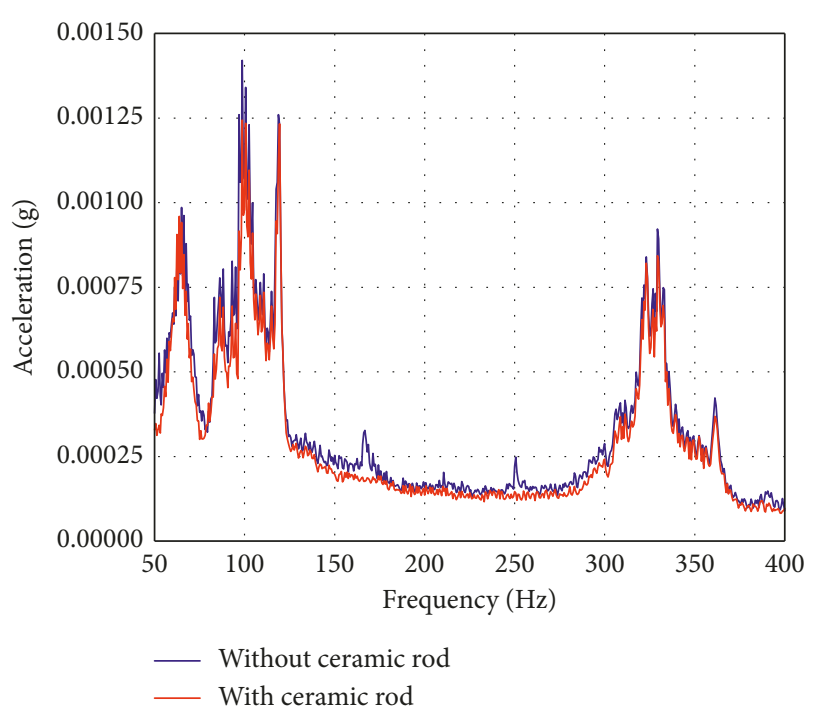

FIGURE 12: Comparison of vibration characteristics of the foundation with rods and without rods under room temperature.

influence of the ceramic road on the damping ratio of the foundation can be ignored.

3.3. Experimental Results and Analysis. The layout of the thermal-vibration joint test system for ship's foundation is shown in Figure 13. To verify the correctness of the finite element analysis, a room temperature test was performed first, and then, the results were compared with the finite element results. The comparison of modal obtained by the test mode and finite element analysis at room temperature are presented in Table 3. It can be seen from the table that the first-order frequency of experimental mode is $9.03 \%$ higher than that of finite element mode, and the second-order frequency of experimental mode is $7.32 \%$ higher than that of finite element mode. Both of their difference is less than $10 \%$, which indicates that the result of simulation is approximate to that from the practical test.

The amplitude of the excitation force is constant $(80 \mathrm{~N})$ during the sine sweeping test. The vibration responses of the

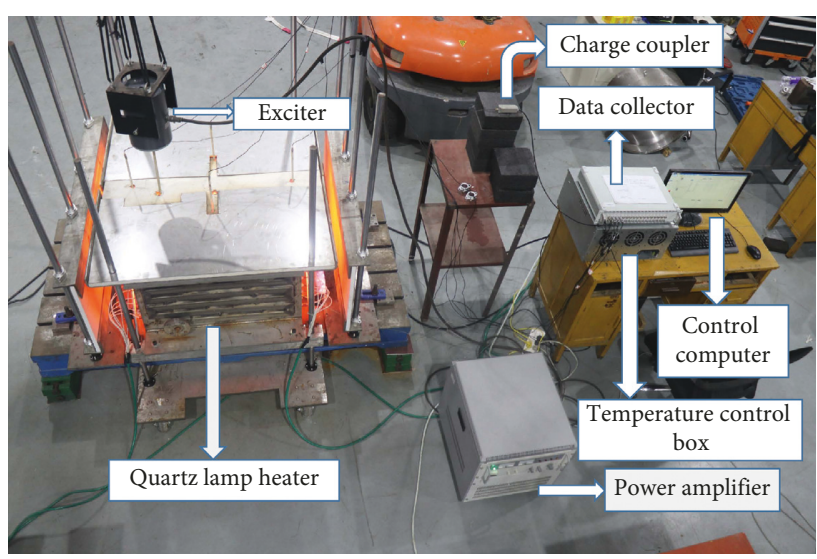

FIGURE 13: Layout of the thermal-vibration joint test system.

TABle 3: Comparison between experimental mode and finite element mode (room temperature).

\begin{tabular}{lcc}
\hline & First order $(\mathrm{Hz})$ & Second order $(\mathrm{Hz})$ \\
\hline Finite element mode & 90.57 & 337.78 \\
Test mode & 98.75 & 362.5 \\
Deviation & $9.03 \%$ & $7.32 \%$ \\
\hline
\end{tabular}

foundation under different temperatures are shown in Figure 14. It is obvious that the higher the heating temperature, the greater the corresponding acceleration admittance. At $200^{\circ} \mathrm{C}$ and $300^{\circ} \mathrm{C}$, the first-order natural frequencies of the foundation are similar, but the corresponding acceleration admittance at $300^{\circ} \mathrm{C}$ is much larger than other operating conditions. At room temperature and $100^{\circ} \mathrm{C}$, the first-order natural frequencies of the foundation are similar, and the response acceleration admittance is also approximately the same, but the resonant frequency lags behind the resonant frequencies at $200^{\circ} \mathrm{C}$ and $300^{\circ} \mathrm{C}$. At the second-order natural frequency, the resonant frequency decreases with the increase of temperature. For the secondorder mode, the higher the temperature, the greater the acceleration admittance. Comparing the results of finite element modal analysis, the first-order vibration energy at each measurement point is larger than the second-order 

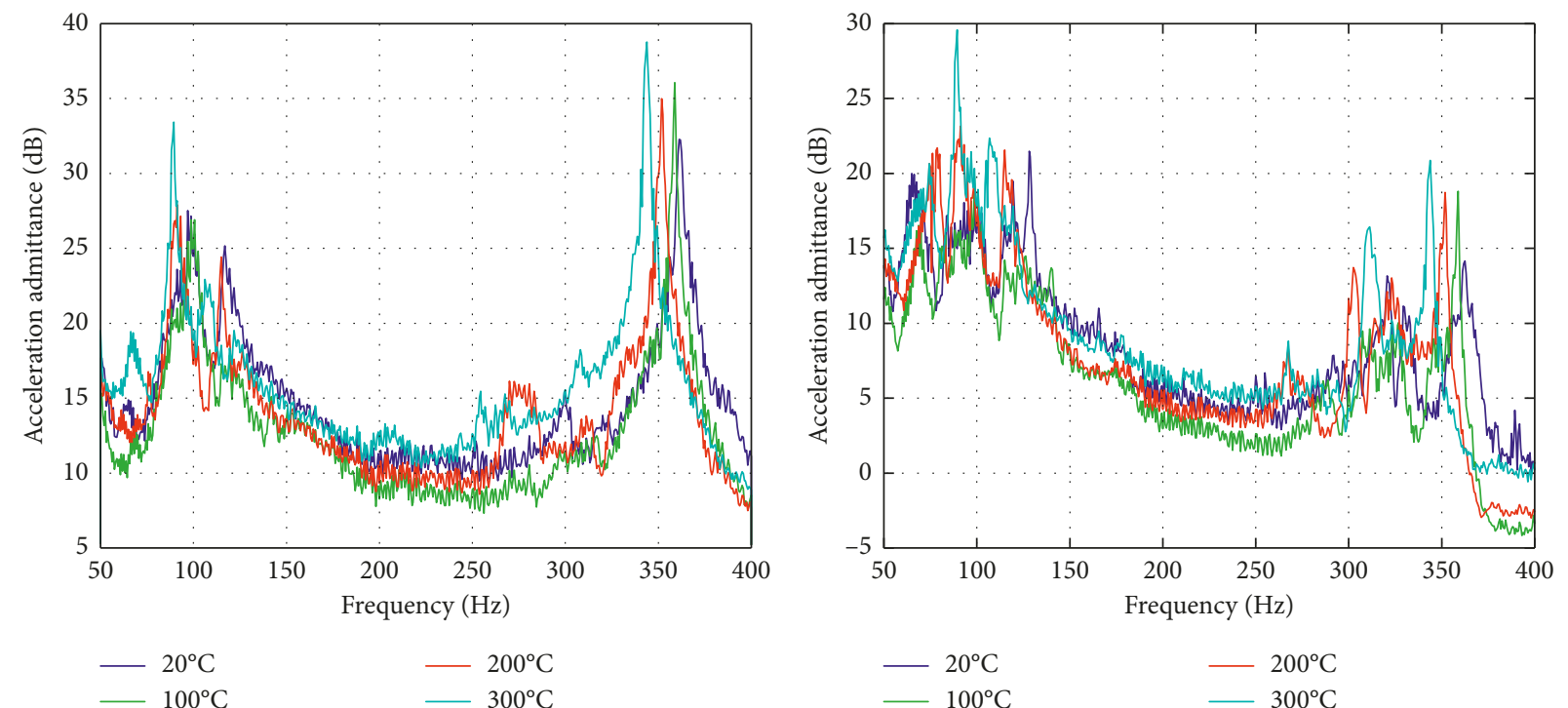

(a)

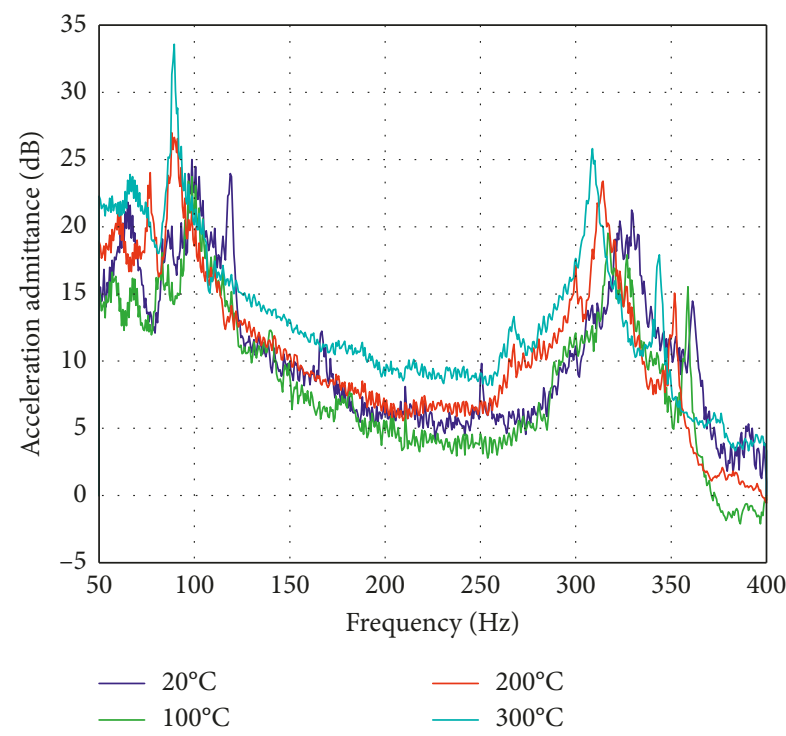

(c)

(b)

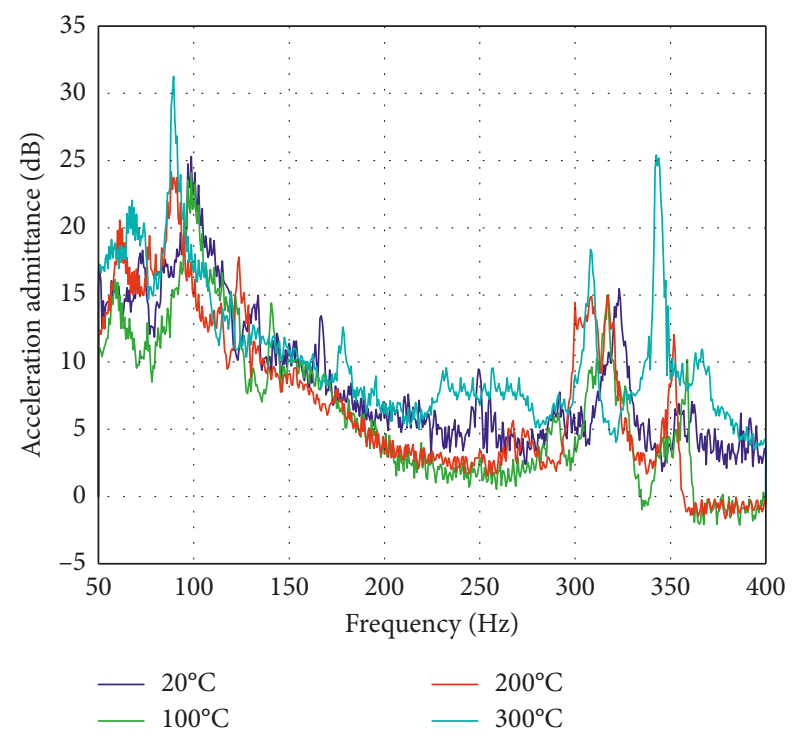

(d)

FIGURE 14: Vibration response of various parts when excited at different temperatures. Vibration response at measurement points (a) 1, (b) 2, (c) 3, and (d) 4 .

vibration energy. However, such a phenomenon appeared in the experiment that the first-order response acceleration admittance at measurement point 1 is greater than the second-order response acceleration admittance. The reason for this phenomenon is that the excitation point is not at the center of the panel. The position of the measurement point 1 from the excitation point is farther than that of the measurement point 3 from the excitation point.

The natural frequency change rates of the foundation at different temperatures are presented in Table 4 . It can be seen from the table that, for measurement point 4 , the second-order formant only appears under $300^{\circ} \mathrm{C}$. According to the previous finite element modal analysis, the amplitude at this point in the second-order modal shape of the foundation is small. The cause of the formant is that the material properties at this point change at $300^{\circ} \mathrm{C}$, and the strength and hardness become small, which make the vibration become severe. The change of the first-order natural frequency with temperature is close to the measuring point 3. The rate of change of the first-order and second-order natural frequencies of the measuring point 2 and the measuring point 1 with temperature basically coincides with each other, and both are less than $10 \%$. The influence of the environment temperature of the foundation on the vibration characteristics is mainly due to the change of the mechanical properties of the material and structure due to the hightemperature environment. The elastic modulus and the stiffness of the structure will decrease with the increase of temperature, resulting in the natural frequency of the structure to decrease with increasing temperature. 
TABLE 4: Natural frequency and rate of change at different temperatures of the foundation (unit: $\mathrm{Hz}$ ).

\begin{tabular}{|c|c|c|c|c|c|c|c|c|}
\hline Measuring point & Order & $20^{\circ} \mathrm{C}$ & $100^{\circ} \mathrm{C}$ & $200^{\circ} \mathrm{C}$ & $300^{\circ} \mathrm{C}$ & \multicolumn{3}{|c|}{ Rate of change } \\
\hline \multirow{2}{*}{1} & First order & 98.75 & 98.75 & 91.25 & 89.375 & 0 & $7.59 \%$ & $9.49 \%$ \\
\hline & Second order & 361.25 & 358.75 & 351.875 & 343.75 & $0.69 \%$ & $2.59 \%$ & $4.84 \%$ \\
\hline \multirow{2}{*}{2} & First order & 98.75 & 98.75 & 91.25 & 89.375 & 0 & $7.59 \%$ & $9.49 \%$ \\
\hline & Second order & 362.5 & 358.75 & 351.875 & 343.75 & $-1.03 \%$ & $2.93 \%$ & $5.17 \%$ \\
\hline \multirow{2}{*}{3} & First order & 98.75 & 98.75 & 88.125 & 89.375 & 0 & $10.76 \%$ & $9.50 \%$ \\
\hline & Second order & 321.875 & 316.875 & 314.375 & 308.75 & $1.55 \%$ & $2.33 \%$ & $4.08 \%$ \\
\hline \multirow{2}{*}{4} & First order & 98.75 & 98.75 & 88.125 & 89.375 & 0 & $10.76 \%$ & $9.50 \%$ \\
\hline & Second order & 1 & I & 1 & 342.5 & l & 1 & 1 \\
\hline
\end{tabular}

As the energy carried by the foundation when it resonates at the first-order frequency is much larger than that at the second-order frequency, this paper only examines the change of the damping ratio of the overall system which includes the foundation and 4 ceramic rods under different temperature conditions in the first-order frequency resonance. The results are shown in Table 5 and Figure 15. As can be seen from Figure 15, the damping ratios of the measuring point 1 and the measuring point 3 at room temperature are larger than that of the measuring point 2 and the measuring point 4 . It can also be seen from Figure 15, with the increase of the temperature, that the gap will become smaller. The damping ratio of each measuring point decreases with the increase of temperature. The reason is that with the increase of temperature, the stiffness of the foundation decrease gradually, and each plate exhibits a softening tendency, so that the dissipation of the excitation energy is reduced on the foundation.

\section{Results}

In this paper, a thermal-vibrational joint test system for ship foundation was developed. By using quartz lamp arrays to radiantly heat the foundation, a $300^{\circ} \mathrm{C}$ high-temperature simulation environment was generated. The foundation was excited in the high-temperature environment by the suspending exciter. Thermal-vibrational joint experiments of the ship's foundation were conducted. The main conclusions, which can be drawn from the conducted experiments, are as follows:

(1) The high-temperature control system can ensure that the temperature of the foundation rises to $300^{\circ} \mathrm{C}$, and the temperature rise curve is highly fitted to the transient thermal simulation.

(2) The foundation mode obtained by finite element analysis is in good agreement with the experimental mode. It can be seen from the finite element mode that when the foundation panel is excited, the maximum value of response acceleration appears on the rib plate, and the deformation on the rib plate is the largest.

(3) The effect of temperature on the vibration characteristics of the foundation is mainly manifested by changes in the natural frequency and damping ratio. For the natural frequency, as the temperature
TABLE 5: Damping ratios of the foundation with four ceramic rods under different temperatures.

\begin{tabular}{lcccc}
\hline Measuring point & $20^{\circ} \mathrm{C}$ & $100^{\circ} \mathrm{C}$ & $200^{\circ} \mathrm{C}$ & $300^{\circ} \mathrm{C}$ \\
\hline 1 & 0.0329 & 0.0268 & 0.0237 & 0.0228 \\
2 & 0.0257 & 0.0234 & 0.0230 & 0.0212 \\
3 & 0.0301 & 0.0253 & 0.0235 & 0.0228 \\
4 & 0.0268 & 0.0230 & 0.0221 & 0.0218 \\
\hline
\end{tabular}

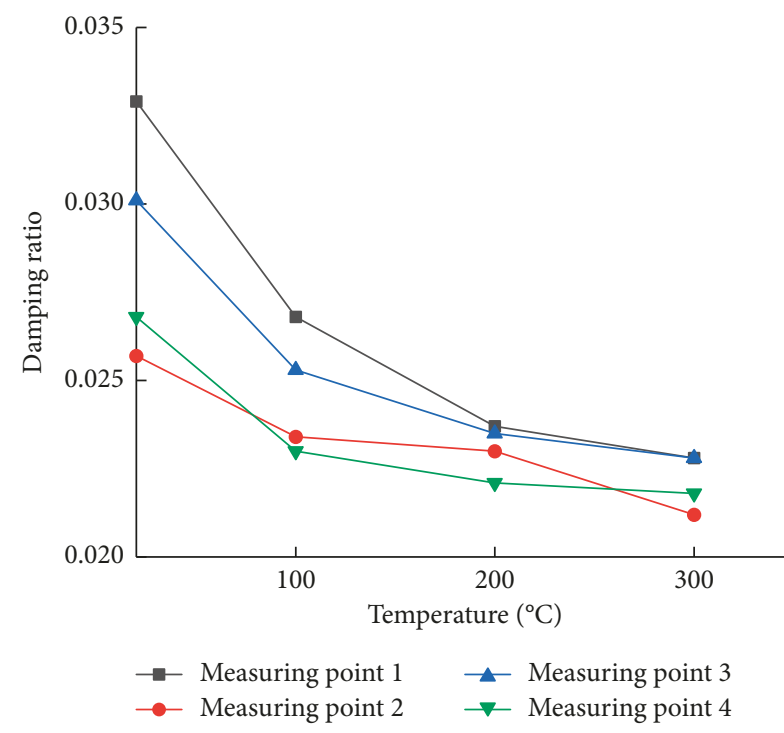

Figure 15: Damping ratio curves.

increases, the first-order natural frequency and the second-order natural frequency advance, and the response acceleration admittance increases. For the damping ratio, as the temperature increases, the damping ratio of the foundation decreases first and then stabilizes, but the overall trend is downward.

The thermal modal performance parameters of the ship's foundation obtained by the thermal-vibrational joint test system provide a reference for the vibration reduction design of the ship's foundation in the high-temperature environment.

\section{Data Availability}

The data used to support the findings of this study are available from the corresponding author upon request. 


\section{Conflicts of Interest}

The authors declare that there are no conflicts of interest.

\section{Acknowledgments}

This work was supported by the National Natural Science Foundation of China (grant number 51805086).

\section{References}

[1] C. D. Che and D. S. Chen, "Structure-borne sound attenuation in a multi-corner structure with attached blocking masses," Journal of Ship Mechanics, vol. 14, no. 9, pp. 1052-1064, 2010.

[2] M. R. Madhav and S. M. AH Jawaid, "Behaviour of composite rigid caisson foundation," Geotechnical. Engineering, vol. 39, no. 2, pp. 105-111, 2008.

[3] C. Saravanan, N. Ganesan, and V. Ramamurti, "Vibration and damping analysis of multilayered fluid filled cylindrical shells with constrained viscoelastic damping using modal strain energy method," Computers \& Structures, vol. 75, no. 4, pp. 395-417, 2000.

[4] H. Cheng, H. B. Li, W. Zhang, B. R. Liu, and Z. Q. Wu, "Effects of radiation heating on modal characteristics of panel structures," Journal of Spacecraft and Rockets, vol. 52, no. 4, pp. 1228-1235, 2015.

[5] H. Larry, Thermal-Structures Testing, NASA Dryden Flight Research Center, Kern, CA, USA, 2008.

[6] A. J. Culler and J. J. Mcnamara, "Studies on fluid-thermalstructural coupling for aerothermoelasticity in hypersonic flow," AIAA Journal, vol. 48, no. 8, pp. 1721-1738, 2010.

[7] D. F. Wu, Y. W. Wang, and Y. Pu, "Thermal modal test of composite wing structure in high-temperature environments up to $1100^{\circ} \mathrm{C}$ for hypersonic flight vehicles," Acta Materiae Compositae Sinica, vol. 32, no. 2, pp. 323-331, 2010.

[8] D. F. Wu, Y. W. Wang, L. Shang, H. T. Wang, and Y. Pu, "Experimental and computational investigations of thermal modal parameters for a plate-structure under $1200^{\circ} \mathrm{C}$ high temperature environment," Measurement, vol. 94, pp. 80-91, 2016.

[9] X. L. Zhang, K. P. Yu, Y. H. Bai, and R. Zhao, "Thermal vibration characteristics of fiber-reinforced mullite sandwich structure with ceramic foams core," Composite Structures, vol. 131, pp. 99-106, 2015.

[10] A. M. Brown, "Temperature-dependent modal test analysis correlation of X-34 FASTRAC composite rocket nozzle," Journal of Propulsion \& Power, vol. 18, no. 2, pp. 284-288, 2002.

[11] B. Pan, L. P. Yu, and D. F. Wu, "Thermo-mechanical response of superalloy honeycomb sandwich panels subjected to nonsteady thermal loading," Materials \& Design, vol. 88, pp. 528-536, 2015.

[12] D. D. L. Chung, "Comparison of submicron-diameter carbon filaments and conventional carbon fibers as fillers in composite materials," Carbon, vol. 39, no. 8, pp. 1119-1125, 2001.

[13] J. K. Kim, C. S. Park, D. W. Lee, S. M. Cho, and C. R. Han, "Measurement of the gauge factor of carbon fiber and its application to sensors," Microelectronic Engineering, vol. 85, no. 5-6, pp. 787-791, 2008.

[14] X. T. Li, ANSYS Workbench Structural Engineering Advanced Application, Water \& Power Press, Beijing, China, 2015.

[15] S. Ravi, P. A. Balakrishnan, C. N. Marimuthu, and C. Sujitha, "Design of synthetic optimizing neuro fuzzy temperature controller for twin screw profile plastic extruder using labview," Intelligent Automation \& Soft Computing, vol. 20, no. 1, pp. 92-100, 2014.

[16] H. X. Cheng, K. Zhang, and L. Cheng, "Design a temperature control system based on labview," Applied Mechanics \& Materials, vol. 644-650, pp. 95-98, 2014.

[17] C. M. Harris, Shock and Vibration Handbook, McGraw-Hill, New York, USA, 1995.

[18] Y. Yong and Y. K. Lin, "Dynamic response analysis of trusstype structural networks: a wave propagation approach," Journal of Sound and Vibration, vol. 156, no. 1, pp. 27-45, 1992.

[19] A. H. V. Flotow, "Disturbance propagation in structural networks," Journal of Sound and Vibration, vol. 106, no. 3, pp. 433-450, 1986.

[20] A. J. Keane and A. P. Bright, "Passive vibration control via unusual geometries: experiments on model aerospace structures," Journal of Sound and Vibration, vol. 190, no. 4, pp. 713-719, 1996. 


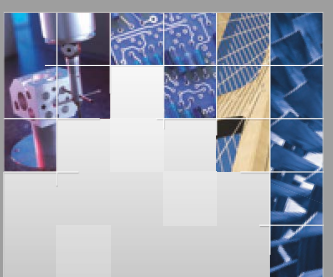

\section{Enfincering}
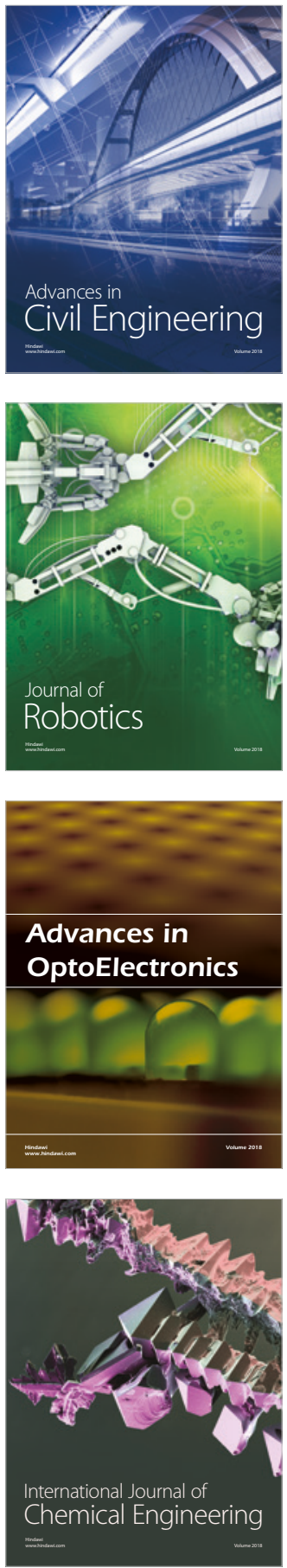

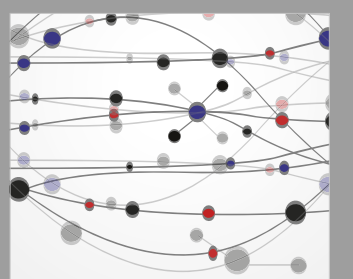

\section{Rotating \\ Machinery}

The Scientific World Journal

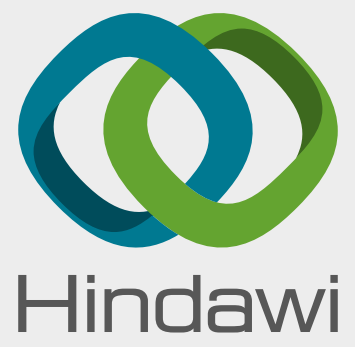

Submit your manuscripts at

www.hindawi.com
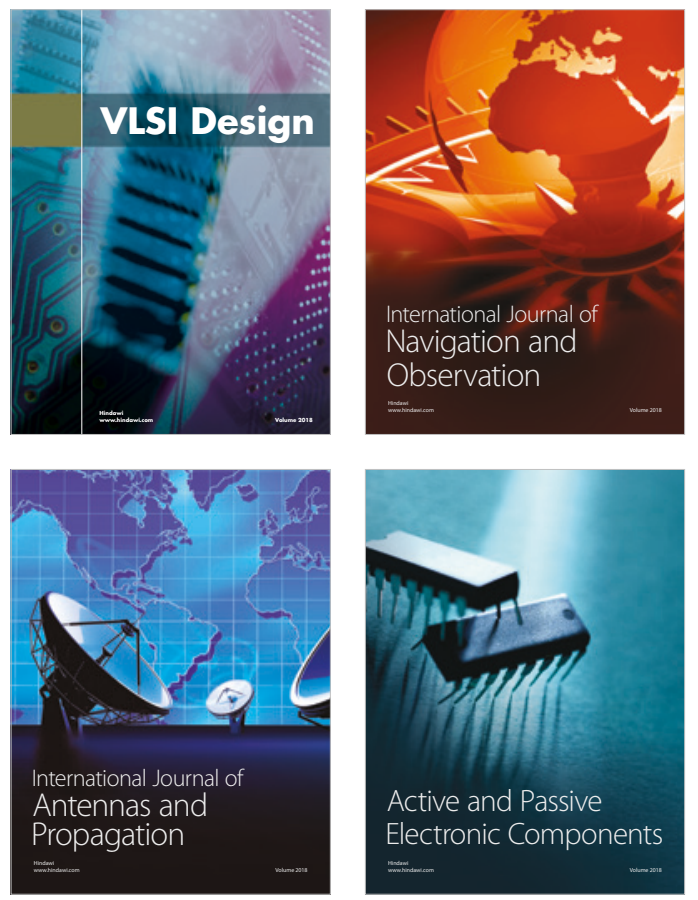
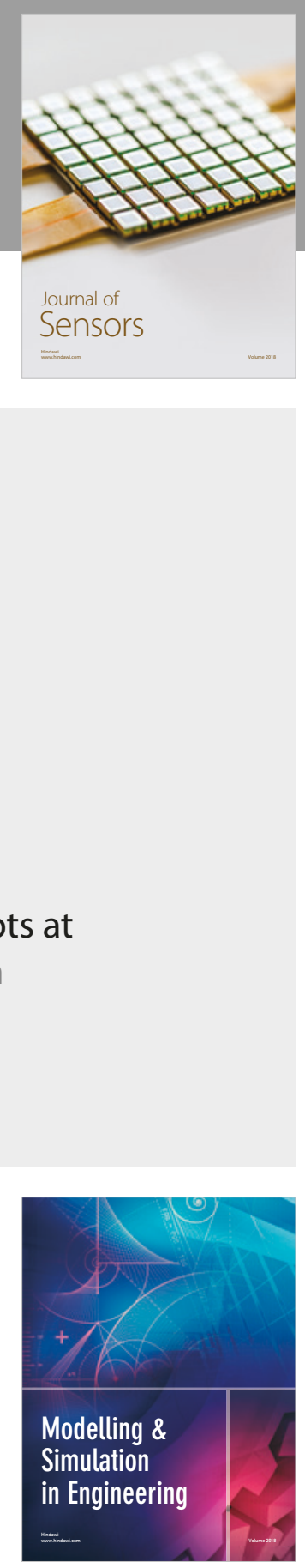

\section{Advances \\ Multimedia}
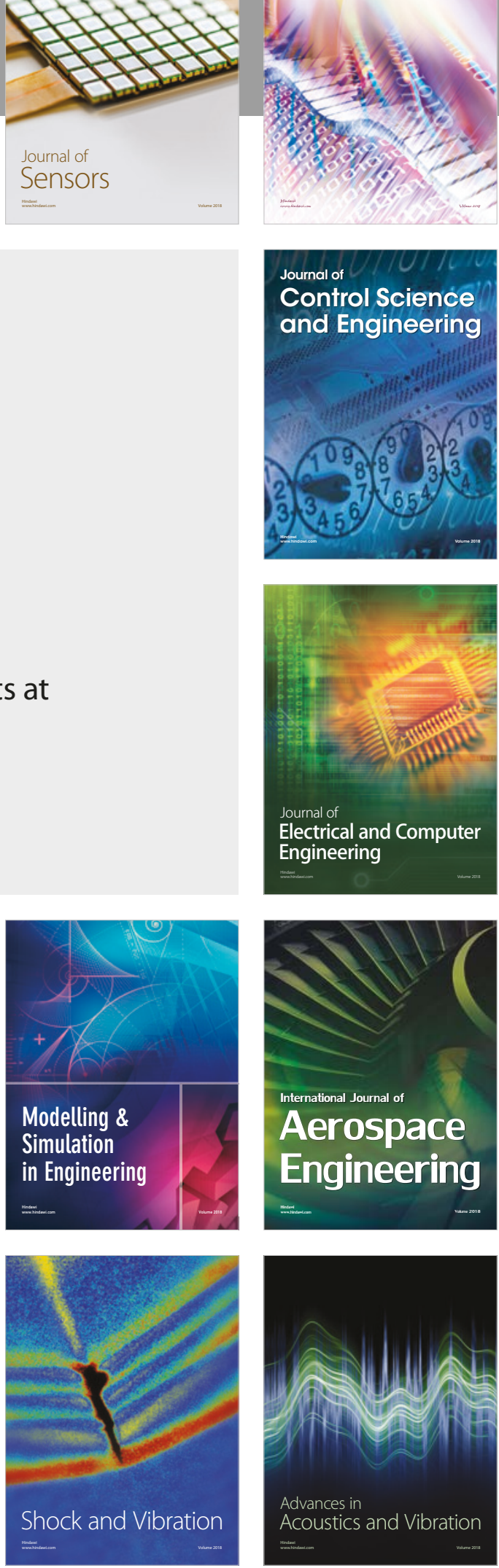